Wang Xuebin and Wang Jincheng*

\title{
Studies on the preparation and properties of biodegradable polyester from soybean oil
}

https://doi.org/10.1515/gps-2017-0098

Received July 30, 2017; accepted October 6, 2017; previously published online December 8, 2017

\begin{abstract}
Crude dimer acid (DA) was prepared with soybean oil (SO) used as raw material and organic montmorillonite as a catalyst. Fourier transform infrared (FTIR) spectroscopy, hydrogen nuclear magnetic resonance $\left({ }^{1} \mathrm{H}\right.$ NMR) and gel permeation chromatography (GPC) were used to characterize the structure of DA. It was demonstrated that the synthesis of crude DA using SO was feasible. A molecular weight of 995-1304 g/mol was obtained by GPC measurement. Then, a type of polyester was synthesized using the crude DA and polyethylene glycol. The effects of reaction temperatures and different catalysts on the conversion rate were explored. The results showed that the esterification conversion rate was improved to $83.13 \%$ when $\mathrm{SnCl}_{2}$ was used as the catalyst, with a reaction temperature of $180^{\circ} \mathrm{C}$ The FTIR, ${ }^{1} \mathrm{H}-\mathrm{NMR}, \mathrm{GPC}$ and TGA were used to characterize the structure and performance of this polyester. The polyester had a molecular weight ranging from 8259 to $10892 \mathrm{~g} / \mathrm{mol}$. In addition, its biodegradable behavior was analyzed by the soil burial test and was compared with that of terephthalic acid. The results showed that the composites prepared from DA had a pronounced effect on weight loss during biodegradation.
\end{abstract}

Keywords: biodegradable; performance; polyester; preparation conditions; soybean oil.

\section{Introduction}

In today's market, the requirements of renewable materials are increasing. First, lower costs for producing renewable fuels are needed compared with those incurred from using petroleum derivatives. Then, other reasons remained, such as the reduction of reserves, high oil prices and the desire for green or biodegradable materials [1]. In addition, social emphasis concerning waste

\footnotetext{
*Corresponding author: Wang Jincheng, School of Chemistry and Chemical Engineering, Shanghai University of Engineering Science, Shanghai, 201620, P.R. China, e-mail: wjc406@126.com

Wang Xuebin: School of Chemistry and Chemical Engineering, Shanghai University of Engineering Science, Shanghai, P.R. China
}

Ә Open Access. (cc)BY @ 2019 Walter de Gruyter GmbH, Berlin/Boston disposal, the depletion of nonrenewable resources and the environment are considered the other main benefits from the application of bio-based products. For these reasons, vegetable oils are often chosen to produce fuels and polymeric materials $[2,3]$.

Waste vegetable oil can be used to produce biodiesel. Researchers focused on biodiesel production using different types of catalyzed transesterification reactions [4]. The conversion, yield and quality of biodiesel are commonly affected by certain parameters, such as membrane reactor, reactive absorption and ultrasonic irradiation. Guzatto et al. [5, 6] modified the double-step transesterification process, in which ethanol was used as a type of transesterification agent to produce biodiesel from vegetable and waste oils. The obtained biodiesels were analyzed by hydrogen nuclear magnetic resonance ( $\left.{ }^{1} \mathrm{H}-\mathrm{NMR}\right),{ }^{13} \mathrm{C}-\mathrm{NMR}$ and Fourier transform infrared (FTIR) spectroscopy as well as by standard physico-chemical techniques. These results indicated that the biodiesel products had high quality and purity. Istadi et al. [7] prepared a novel type of solid acid catalysts, sulphated zinc oxide, in the transesterification of soybean oil with methanol to produce biodiesel. From the testing results, this catalyst exhibited properties of being a good candidate catalyst for the transesterification of soybean oil to produce biodiesel. Zargar et al. [8] used waste vegetable oil to replace a natural agent for bitumen. The properties of the original, aged and rejuvenated bitumen were all evaluated. The results showed that the physical properties of aged bitumen group 40/50 was almost the same as the properties of the original bitumen (80/100) with the addition of $3-4 \%$ of waste vegetable oil.

In addition, because of their biodegradability, nontoxicity and low production cost, vegetable oils have also been used as raw materials for the preparation of novel polymers instead of traditional polymers. Liu and Erhan [9] synthesized biopolymers based on soybean oil (SO) using the cationic polymerization method. This process occurred in the supercritical carbon dioxide solvent and initiated by the boron trifluoride diethyl etherate. The molecular weight of the obtained polymers ranged from 21,842 to $118,300 \mathrm{~g} / \mathrm{mol}$. Guo et al. [10] investigated the preparation of the rigid polyurethane foams from polyols derived from soybean oil, and found that these foams possessed good mechanical and thermoinsulating properties together with 
better thermal degradation and thermal oxidation properties compared with that of foams synthesized from petrochemical origin. Sahoo Sushanta et al. [11] used the in situ method to synthesize a novel type of bioresin and epoxidize SO to blend with epoxy in different ratios. It may act as a kind of reactive diluent, thus improving the processibility and toughened nature of the epoxy. Their results showed that $20 \mathrm{wt} \%$ bioresin in the composite improved impact strength compared with the virgin epoxy. However, the above methodology only gave two ways for the utilization of vegetable oils. To date, the preparation and characterization of dimer acid (DA) and polyester using vegetable oils had not been systematically researched.

In the present work, crude DA and a type of biodegradation polyester was prepared using SO. The preparation, structure, morphology, thermal stability and biodegradation behavior of this polymer were investigated.

\section{Materials and methods}

\subsection{Materials}

The SO employed in this study was bought from Legou Supermarket (Shanghai, China). The stannous chloride, ammonia acid, phenolphthalein, concentrated sulfuric acid, acetic acid, acetone, acetate, ethanol, potassium hydroxide and terephthalic acid (TA) were chemically pure and obtained from the Shanghai Guoyao Agent Company (Shanghai, China). The polyethylene glycol (PEG) of chemical grade was obtained from Zhenjiang Huaxing New Materials Co., Ltd. (Jiangsu, China). The organic montmorillonite was homemade and of industrial grade [12].

\subsection{Preparation of DA and polyester}

About $10 \mathrm{~g}$ of SO was added into a three-necked flask with $5 \mathrm{ml}$ of acetate buffer. Then, $20 \mathrm{ml}$ of acetone and ethanol with a ratio of 1:1 was added to the flask. By titration with $0.1 \mathrm{~N} \mathrm{KOH}$ aqueous solution, the total fatty acid generated in the mixture was determined.

Next, $1.2 \mathrm{~g}$ of organic montmorillonite was dissolved in $100 \mathrm{~g}$ of the fatty acid. The above mixture was then added into a three-necked flask, heated to $200^{\circ} \mathrm{C}$ and treated at this temperature for $6 \mathrm{~h}$ to allow the reaction to proceed completely. Crude DA was thus prepared. Then, $14 \mathrm{~g}$ of crude DA was poured into a three-necked flask, to which $25 \mathrm{~g}$ of PEG and $0.12 \mathrm{~g}$ of catalyst were added. This mixture was cured for $6 \mathrm{~h}$ at $190^{\circ} \mathrm{C}$. Thus, a type of polyester was obtained.

\subsection{Characterization of the DA and polyester}

The FTIR was performed on a Nicolet Avatar 370 spectrophotometer. The ranges were between 4000 and $700 \mathrm{~cm}^{-1}$ with a resolution of $2 \mathrm{~cm}^{-1}$. The pellets were formed by grinding samples with $\mathrm{KBr}$. The spectra with good signal-to-noise ratios were obtained by 64 scans.
The ${ }^{1} \mathrm{H}-\mathrm{NMR}$ was conducted on a Bruker AV600 spectrometer. Deuterated chloroform $\left(\mathrm{CDCl}_{3}, 99.8 \%\right)$ was used to prepare the sample solutions for testing. The tetrahydrofuran was used to dissolve the above liquids. An internal standard was referred to tetramethylsilane (TMS).

The molecular weight was measured by gel permeation chromatography (GPC) (PL-GPC50, the relative molecular mass range: 500 19,000, British). Tetrahydrofuran was used as the mobile phase with a flow rate of $1 \mathrm{ml} / \mathrm{min}$.

Thermogravimetric analysis (TGA and DTG) was conducted on a Linseis PT-1000 microbalance. This test was conducted under a nitrogen atmosphere in an increasing rate of temperature, $20^{\circ} \mathrm{C} / \mathrm{min}$. In addition, $10 \mathrm{mg}$ of the samples was used during the measurement.

The acid values of the polyester were measured according to the Chinese National Standard HG/T 2708-95. The following formula was used in the calculation of the values:

$$
A_{V}=56.1 \frac{\left(V_{1}-V_{2}\right) T}{M},
$$

where $A_{V}$ is the acid value of the sample, $V_{1}$ is the titration of the sample standard solution of potassium hydroxide $(\mathrm{ml}), V_{2}$ is the blank test of the titration of the potassium hydroxide standard solution consumed (ml), $T$ is the standard equivalent concentration of potassium hydroxide solution and $M$ is the specimen weight (g).

The soil burial test was conducted to characterize the biodegradable properties. The composites were cut into $60 \mathrm{~mm} \times 30 \mathrm{~mm} \times 2 \mathrm{~mm}$ portions. Their weights were measured, after which they were buried in soil with a depth of $15.24 \mathrm{~cm}$. After a certain number of days, they were taken out from the soil. In addition, the soil was removed from their surface by washing with distilled water. The samples were dried in an oven for $6 \mathrm{~h}$ and kept at room temperature for $24 \mathrm{~h}$. Finally, their weight loss was measured, and thus the biodegradability property was obtained.

\section{Results and discussion}

\subsection{Preparation of the DA}

\subsubsection{Preparation mechanism of the DA from SO}

The hydrolysis of SO under acid conditions is shown in Scheme 1. The products of this hydrolysis were glycerol and fatty acid. SO is considered a type of semidrying oil due to its lower double-bond density. Among others, it is the second cheapest vegetable oil [13]. The structure of SO consists of the tri-glyceride ester of fatty acids $[8,14]$. The unsaturation in the fatty acid makes it an ideal monomer for preparing other polymers. However, its reactivity is rather low due to its multiple chain structure.

The preparation mechanism of DA from the hydrolysis product of SO was via the Diels-Alder reaction. In this reaction, a conjugated diene is produced from the non-conjugated diene. Then, it reacts with a double bond in another unsaturated fatty group. This reaction could be an intramolecular cycloaddition from which cyclic products could be 

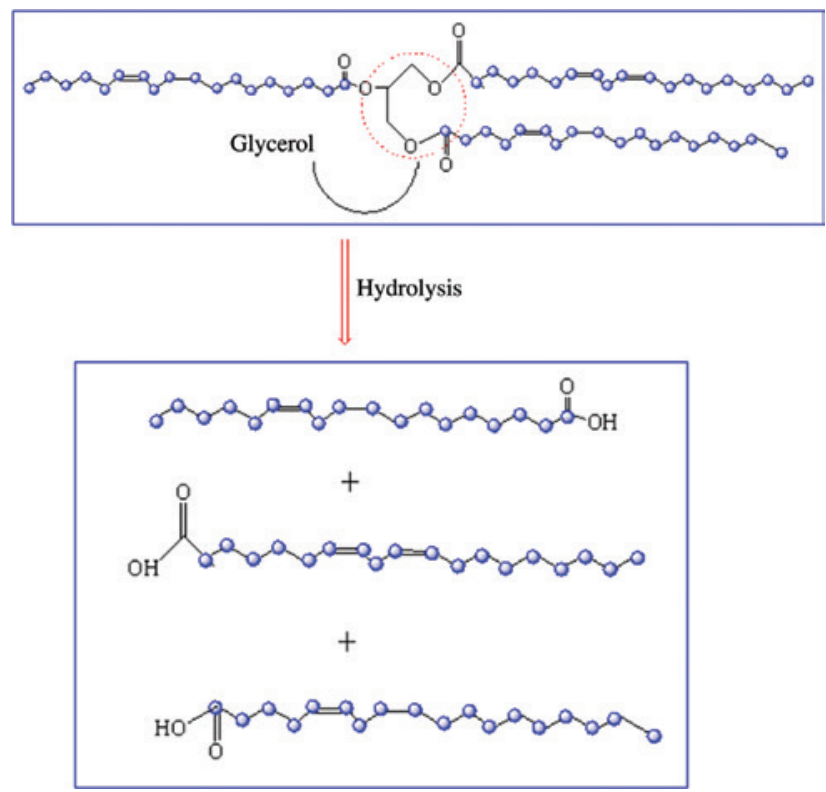

Scheme 1: Hydrolysis of SO.

formed [15]. Polymers with high molecular weight can be synthesized between dimers and trimers through polymerization and intermolecular Diels-Alder reactions.

\subsubsection{Characterization of the DA}

Photos of the DA are shown in Figure 1. As can be seen from the photo, SO is a kind of transparent liquid with a pale yellow color, whereas the crude DA is brown, viscous and can be crystallized at low temperatures.

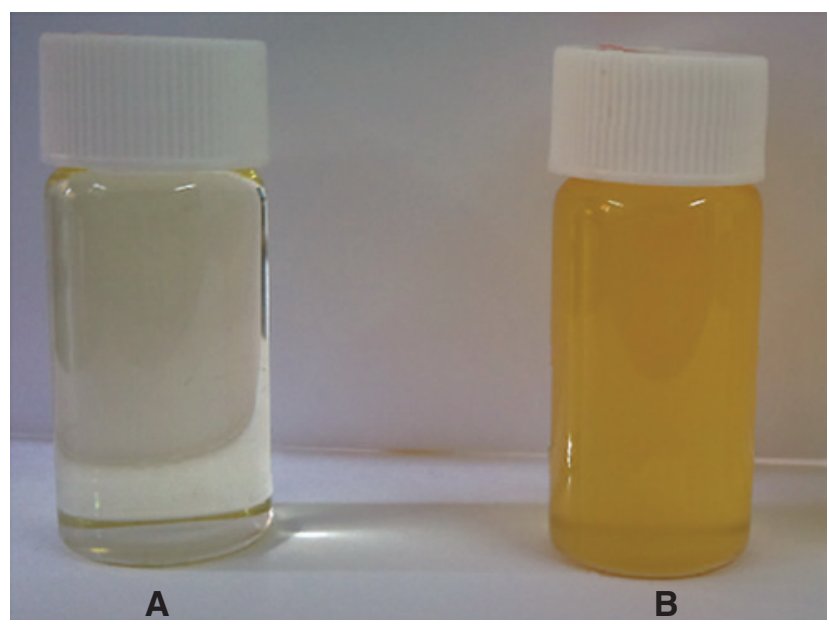

Figure 1: Digital photos of the raw material and the intermediate (A) SO, (B) DA. These photos were conducted at an ambient temperature.
From the FTIR spectrum of SO, Figure 2A, three obvious absorption peaks were observed at 3000, 2800 and $1550 \mathrm{~cm}^{-1}$, respectively. These peaks were related to the stretching and bending vibrations of $\mathrm{C}-\mathrm{H}$ bonds in the compound. The peaks at $3000-3100 \mathrm{~cm}^{-1}$ and $950 \mathrm{~cm}^{-1}$ were ascribed to the stretching and bending vibrations of $=\mathrm{CH}$. The very obvious absorption peak at $1750 \mathrm{~cm}^{-1}$ resulted from the stretching vibrations of the $\mathrm{C}=0$ groups. In addition, the peaks at $1180 \mathrm{~cm}^{-1}$ resulted from the C-O bonds, indicating that the - $\mathrm{COO}$ groups remained in the structure.

In the spectrum of DA (Figure 2B), strong peaks appeared at 3000-2800 and $1400-1500 \mathrm{~cm}^{-1}$, which resulted from the stretching and bending vibrations of the $\mathrm{C}-\mathrm{H}$ bonds in the structure. The absorption peaks at $3000-3100 \mathrm{~cm}^{-1}$ disappeared, illustrating that the double bond reactions and $\alpha$-carbon reaction occurred in this olefin $[16,17]$. The absorption peak at $1720 \mathrm{~cm}^{-1}$ resulted from the stretching vibrations of the $\mathrm{C}=\mathrm{O}$ bonds, and those at $1180 \mathrm{~cm}^{-1}$ were ascribed to $\mathrm{C}-\mathrm{O}$. This demonstrated that the -COO groups also existed in this molecule. Wider peaks appeared at $1150-1350 \mathrm{~cm}^{-1}$, which resulted from the bending vibration of $=\mathrm{CH}$ caused by the cyclohexene. This proved that the cyclohexene structure existed in the molecular structure of DA [18]. In other words, the DA product had the typical structure of a dimer.

The ${ }^{1} \mathrm{H}$-NMR spectra of SO and DA are shown in Figure 3. the signals at 5.2-5.4 ppm, shown in Figure 3A, can be ascribed to the olefinic hydrogens, whereas those

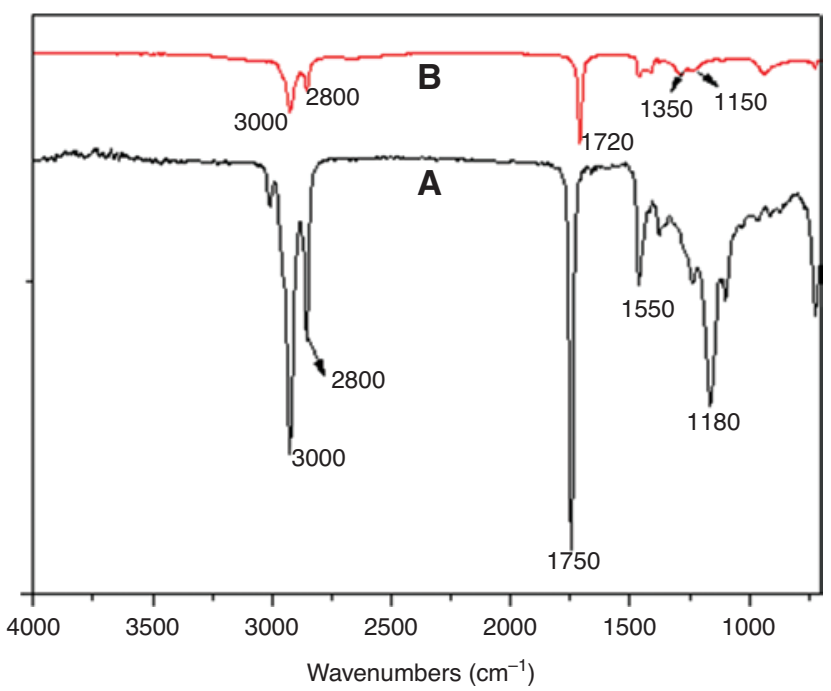

Figure 2: FTIR of the raw material and the intermediate (A) SO, (B) DA. The scanning was performed in a range between 4000 and $700 \mathrm{~cm}^{-1}$ with a resolution of $2 \mathrm{~cm}^{-1}$. 
A

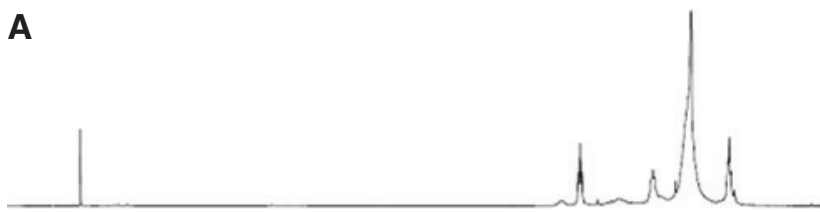

B

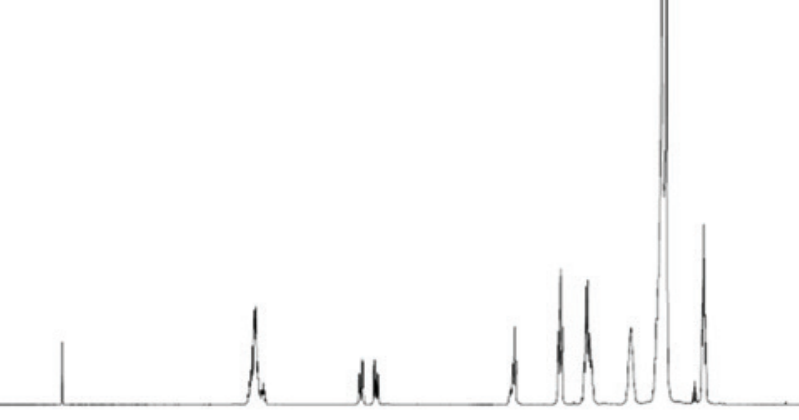

$\begin{array}{llllllllllllllll}7.5 & 7.0 & 6.5 & 6.0 & 5.5 & 5.0 & 4.5 & 4.0 & 3.5 & 3.0 & 2.5 & 2.0 & 1.5 & 1.0 & 0.5\end{array}$ ppm

Figure 3: The ${ }^{1} \mathrm{H}-\mathrm{NMR}$ spectra of the raw material and the intermediate (A) SO, (B) DA. Deuterated chloroform ( $\mathrm{CDCl}_{3}, 99.8 \%$ ) was used to prepare the sample solutions for testing.

at 4.1-4.4 ppm were the methylene protons in the $-\mathrm{CH}_{2}$ adjacent to the $\mathrm{C}=\mathrm{C}$ bond. The signals at $1.1-2.9 \mathrm{ppm}$ also resulted from the methylene protons of $-\mathrm{CH}_{2}-\mathrm{CH}_{2}-\mathrm{CH}_{2}$ - in the glycerin. In Figure 3B, the peaks at 1.2-1.5 and 2.1$2.4 \mathrm{ppm}$ were greatly decreased compared with the proton in SO. The peaks at 5.2-5.4, 4.1-4.5 and $2.8 \mathrm{ppm}$ also disappeared. This observation illustrated the reduced number of $\mathrm{C}=\mathrm{C}$ bonds and the successful polymerization of DA $[9,15,19]$.

The GPC results of the prepared DA are summarized in Table 1 . As can be seen, about $87 \%$ of the average molecular weights ranged from 995 to $1304 \mathrm{~g} / \mathrm{mol}$, which were higher than the theoretical average molecular weight of $560 \mathrm{~g} / \mathrm{mol}$. This was due to the complex components in the edible SO, which contained different ratios of palmitic acid, arachidic acid and stearic acid. The unsaturated groups in these components may participate in the conjugation reactions, thus increasing the molecular weight of DA [20].

Table 1: The GPC results of DA.

\begin{tabular}{lrrrr}
\hline DA & $\overline{\boldsymbol{M}}_{n}$ & $\overline{\boldsymbol{M}}_{w}$ & $\overline{\boldsymbol{M}}_{z}$ & Ratio (\%) \\
\hline 1 & 3402 & 4817 & 7668 & 13.05 \\
2 & 1304 & 1314 & 1324 & 44.89 \\
3 & 995 & 1012 & 1025 & 42.06 \\
\hline
\end{tabular}

\subsection{Preparation of the DA/PEG polyester}

\subsubsection{Preparation mechanism of the DA/PEG polyester}

The preparation process of polyester from DA and PEG is shown in Scheme 2. The main factors that affected the esterification between DA and PEG were dosage, reaction time, reaction temperature and reactant ratios. The experiments were conducted to investigate these factors. Two reaction temperatures, $180^{\circ} \mathrm{C}$ and $190^{\circ} \mathrm{C}$, were selected due to the limited experimental conditions. In this experiment, the ratios of the reactants and the reaction time were fixed, but the catalyst and reaction temperature were changed.

Table 2 shows the results of the acid values and ester conversion rates using different types of catalyst. It can be seen that the conversion rate was the highest when $\mathrm{SnCl}_{2}$ was used as the catalyst. The catalytic mechanism [21-23] of $\mathrm{SnCl}_{2}$ was illustrated as follows. First, $\mathrm{SnCl}_{2}$ had antioxidant abilities; when it was added to the reaction system,
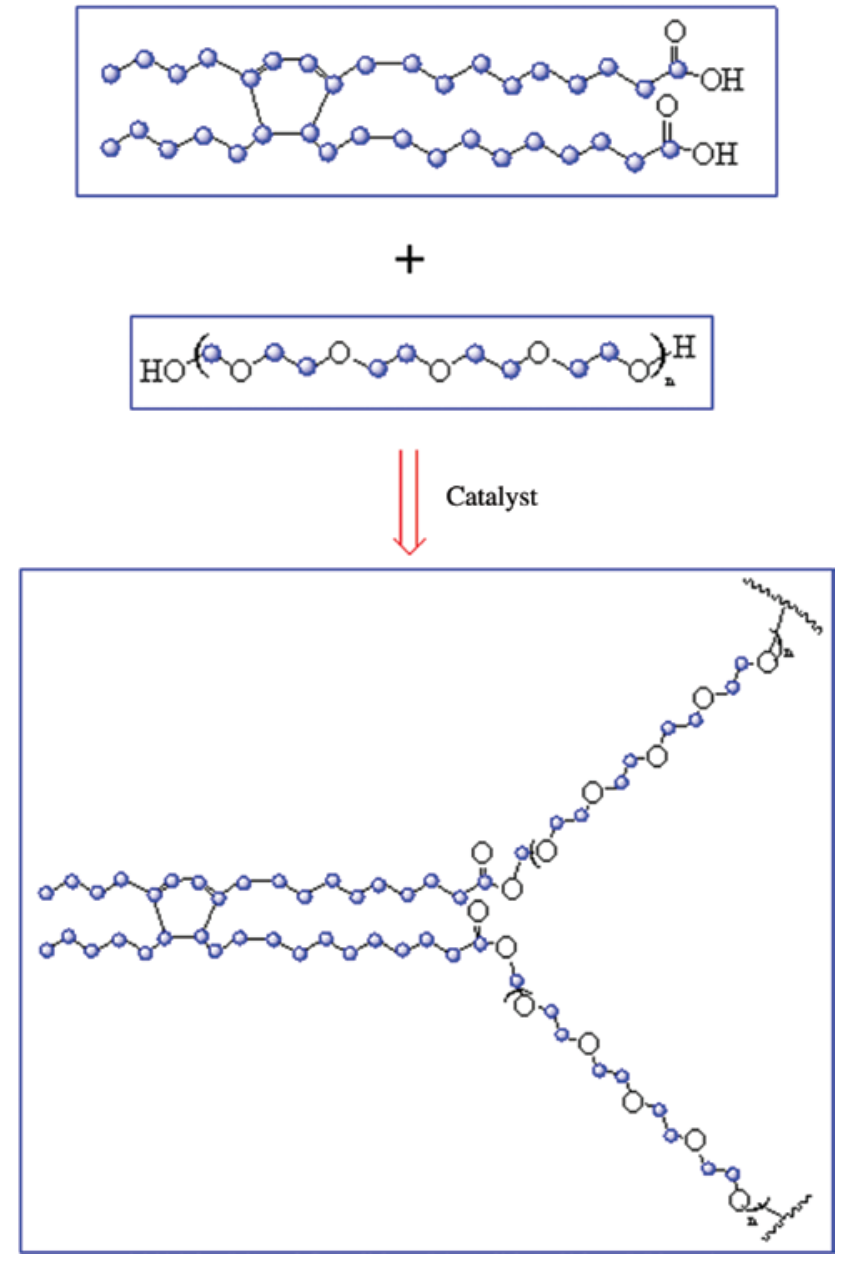

Scheme 2: The preparation process of polyester from DA and PEG. 
Table 2: The acid value and ester conversion rate of polyester.

\begin{tabular}{lrcrr}
\hline Catalyst & $\begin{array}{r}\text { Temperature } \\
\left({ }^{\circ} \mathrm{C}\right)\end{array}$ & Mass (g) & $\begin{array}{r}\text { Consummation } \\
\text { of KOH (ml) }\end{array}$ & $\begin{array}{r}\text { Conversion } \\
\text { rate (\%) }\end{array}$ \\
\hline No. & 180 & 2.2118 & 26.80 & 60.26 \\
Stannous chloride & 180 & 2.3411 & 16.45 & 83.13 \\
Stannous chloride & 190 & 2.1947 & 17.50 & 79.76 \\
Concentrated sulfuric acid & 180 & 2.0742 & 20.70 & 71.38 \\
Concentrated sulfuric acid & 190 & 2.2293 & 25.00 & 64.35 \\
Glacial acetic acid & 180 & 2.2163 & 24.60 & 64.98 \\
Glacial acetic acid & 190 & 2.2707 & 26.30 & 62.32 \\
Ammonia acid & 180 & 2.1545 & 25.90 & 61.16 \\
Ammonia acid & 190 & 2.6653 & 31.95 & 58.00 \\
\hline
\end{tabular}

the incidence of side effects was effectively reduced and the esterification rate increased. Second, the catalyst $\mathrm{SnCl}_{2}$ provided a no-electron atomic orbit and combined with the lone pair electrons of the oxygen in the carbonyl. This enhanced the positive electrical charge of the carbon in carbonyl. Due to these reasons, the oxygen in the hydroxyl groups of PEG combined with the carbon atoms in the carbonyl. Thus, the appropriate amount of $\mathrm{SnCl}_{2}$ was suitable to accelerate this reaction.

In Table 2, it was shown that the conversion rate under $180^{\circ} \mathrm{C}$ was $83.13 \%$, which was higher than that under $190^{\circ} \mathrm{C}$. The decarboxylation of the fatty acid can be caused by high temperatures. This increased the pressure in the flask, which resulted in an increase of the monomer content and a decrease of the acid value and viscosity [24]. Therefore, using $\mathrm{SnCl}_{2}$ as catalyst and setting the the reaction temperature to $180^{\circ} \mathrm{C}$ were the optimal conditions for the preparation of the polyester.

\subsubsection{Characterization of the DA/PEG polyester}

Figure 4 presents the FTIR spectrum of the DA/PEG polyester. The table shows two obvious absorption peaks at $3300-3700$ and $3000-2800 \mathrm{~cm}^{-1}$, respectively. These corresponded to the stretching vibrations of the $\mathrm{O}-\mathrm{H}$ and $\mathrm{C}-\mathrm{H}$ bonds in the structure. The obvious peak at $1730 \mathrm{~cm}^{-1}$ resulted from the stretching vibration of the $\mathrm{C}=\mathrm{O}$ group. Those at $1160 \mathrm{~cm}^{-1}$ were related to the $\mathrm{C}-\mathrm{O}$ bond. This showed that the -COO groups existed in the polymer. There were no absorptions at $1800-2700 \mathrm{~cm}^{-1}$, indicating that the sample had a high purity [25]. In conclusion, the polyester was properly synthesized by the DA and PEG.

The ${ }^{1} \mathrm{H}-\mathrm{NMR}$ spectrum of the polyester is illustrated in Figure 5. The chemical shifts between 3.5 and $4.1 \mathrm{ppm}$ resulted from the $\mathrm{CH}_{2}-\mathrm{O}$ group. The bands appearing between 2.0 and $2.5 \mathrm{ppm}$ resulted from the $-\mathrm{COCH}_{3}$ structure in the remaining monomers. Moreover, the multiple

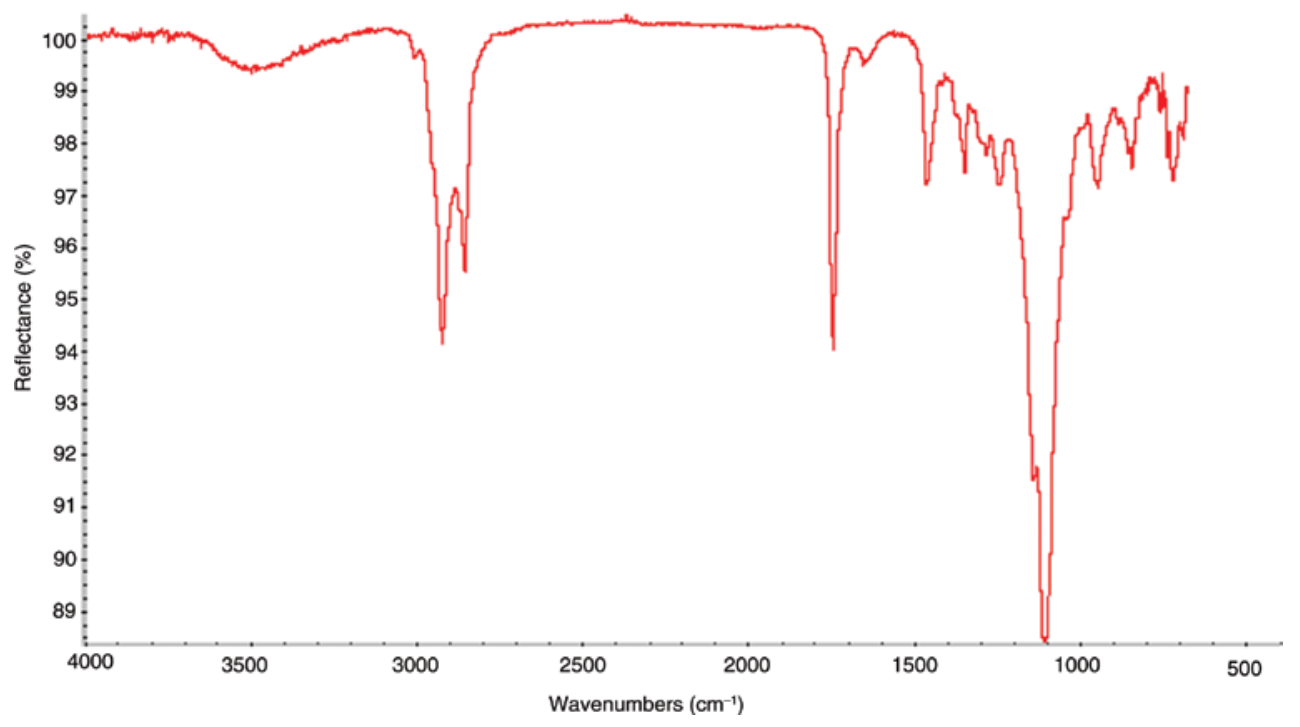

Figure 4: The FTIR of DA/PEG polyester. 


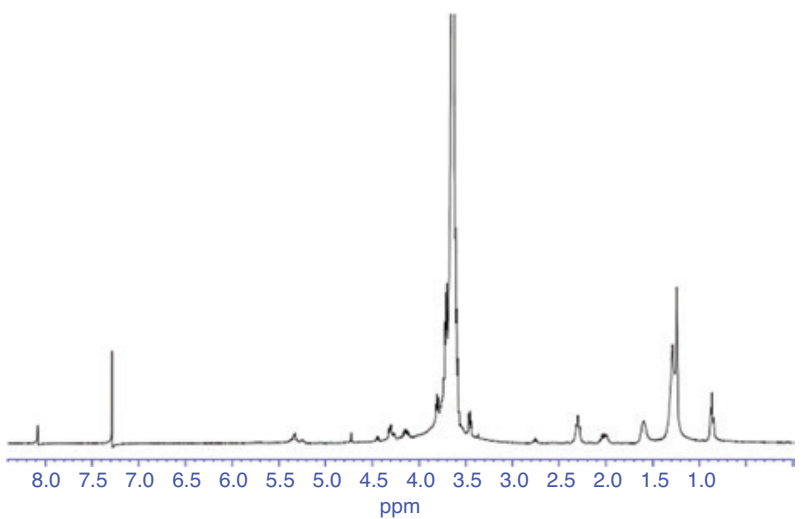

Figure 5: The ${ }^{1} \mathrm{H}-\mathrm{NMR}$ spectrum of $\mathrm{DA} / \mathrm{PEG}$ polyester.

peaks at 0.8-1.7 ppm may be due to the complicated chemical environment of the $\mathrm{H}$ protons in the methyl groups among the macromolecular chains [26].

The TGA and DTG curves of the DA/PEG polyester are shown Figure 6. Its degradation under air occurred in three successive steps. Initial weight loss was first shown between $250^{\circ} \mathrm{C}$ and $320^{\circ} \mathrm{C}$. This was due to the degradation of the synthetic monomer, such as DA and PEG, in the resin. The second step was observed between $320^{\circ} \mathrm{C}$ and $440^{\circ} \mathrm{C}$. This was attributed to the degradation of the alkane hydrocarbon groups in the structure. The third step appeared between $440^{\circ} \mathrm{C}$ and $510^{\circ} \mathrm{C}$, and showed the highest degradation rate at about $440^{\circ} \mathrm{C}$. This had something to do with the degradation of the resin residue sin. This resin showed a characteristic thermal behavior of polymer resins [27]. In conclusion, the results above demonstrated that this polyester resin was successfully prepared.

Table 3 records the GPC results of the DA/PEG polyester. About $55 \%$ of the molecular weight of the polyester was 10,892 $\mathrm{g} / \mathrm{mol}$, whereas $45 \%$ was $8259 \mathrm{~g} / \mathrm{mol}$. This showed that the condensation reaction was not sufficient.

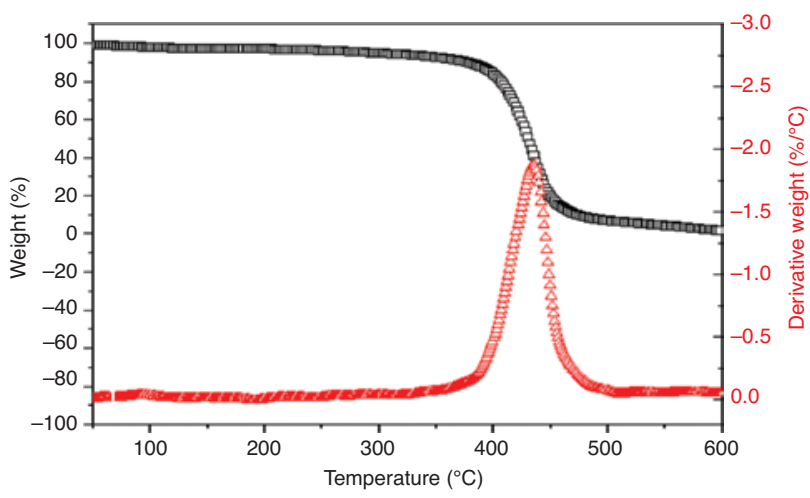

Figure 6: The TGA and DTG curves of DA/PEG polyester.
Table 3: GPC results of DA/PEG polyester.

\begin{tabular}{lrrrr}
\hline DA/PEG polyester & $\overline{\boldsymbol{M}}_{n}$ & $\overline{\boldsymbol{M}}_{w}$ & $\overline{\boldsymbol{M}}_{z}$ & Ratio (\%) \\
\hline 1 & 10,892 & 11,548 & 12,892 & 55.5 \\
2 & 8259 & 9564 & 10,257 & 44.5 \\
\hline
\end{tabular}

It can be inferred that the dehydration reaction of the crude DA occurred, and the product with a carboxyl group was reduced. Hence, the carboxyl functional groups were unable to form a double DA, leading to a capped reaction in PEG. This phenomenon was not beneficial for the possible formation of polyesters with high molecular weights. In addition, according to the principle of kinetics, the formation of the polyester may be blocked due to the presence of water [28].

The biodegradability of the polyester was determined by measuring the weight loss of the composite during the soil burial test. Figure 7 describes the percentage weight loss of the biodegraded polymers after 35 days. In order to know its biodegradable property, the polyesters prepared from the crude DA and PEG were compared with those from TA and PEG.

The weight loss showed an approximately linear relation with degradation time for both materials. The weight loss of the polyester prepared from TA was about $25 \%$ after biodegradation for 15 days. The average degradation rate was at a relatively lower rate of $1.6 \%$. In comparison, the weight loss of polyester prepared from crude DA was at $60 \%$. The average degradation rate was about $4 \%$ per day. These data indicated that the weight loss of the polyester prepared from the DA was relatively higher compared with that prepared from TA. In other words, the presence of DA

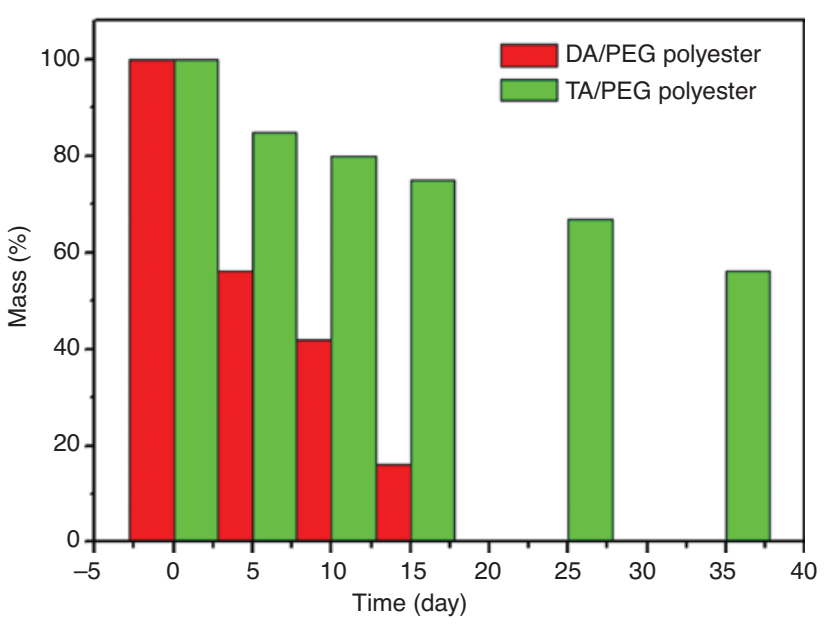

Figure 7: The weight losses of different polyesters under the soil burial test. 
prepared from SO had a pronounced effect on the weight loss during biodegradation.

\section{Conclusions}

The biodegradable polyester was prepared by a novel method using SO. The new method was based on the first preparation of the DA. The proposed method was feasible for the synthesis of crude DA by using SO. The experimental conditions were the combination of the following conditions: temperature of $200^{\circ} \mathrm{C}$, organic montmorillonite as a catalyst, and the reaction time of $6 \mathrm{~h}$. The structure and properties of DA were analyzed by FTIR, ${ }^{1} \mathrm{H}-$ NMR and GPC. The DA had an average molecular weight of $995-1304 \mathrm{~g} / \mathrm{mol}$.

The optimal experimental conditions for the preparation of the biodegradation polyesters were determined: temperature of $180^{\circ} \mathrm{C}$ and $\mathrm{SnCl}_{2}$ as the catalyst. The structure and properties of the polyester were analyzed by FTIR, ${ }^{1} \mathrm{H}-\mathrm{NMR}, \mathrm{GPC}$ and soil burial test. The polyester had a molecular weight of $8259-10,892 \mathrm{~g} / \mathrm{mol}$. Meanwhile, the polyester prepared from the crude DA and PEG showed a better biodegradation property than that obtained from TA and PEG.

Acknowledgments: This work was financially supported by the Capacity Building Project of Some Local Colleges and Universities in Shanghai (Grant No. 17030501200).

\section{References}

[1] Zahira Y, Masita M, Mohammad A, Zahangir A, Kamaruzaman S. Renew. Sust. Energ. Rev. 2013, 18, 184-193.
[2] Wang Y, Ou S, Liu P, Zhang Z. Energ. Convers. Manage. 2007, 48, 184-188.

[3] Pinzi S, Garcia IL, Lopez-Gimenez FJ, Luque de Castro MD, Dorado G, Dorado MP. Energ Fuel 2009, 23, 2325-2341.

[4] Man KL, Keat TL, Abdul RM. Biotechnol. Adv. 2010, 28, 500-518.

[5] Guzatto R, Defferrari D, Reiznautt QB, Cadore IR, Samios D. Fuel 2012, 92, 197-203.

[6] Guzatto R, Luis de Martini T, Samios D. Fuel Process. Technol. 2011, 92, 2083-2088.

[7] Istadi I, Anggoro DD, Buchori L, Rahmawati DA, Intaningrum D. Procedia Environ. Sci. 2015, 23, 385-393.

[8] Zargar M, Ahmadinia E, Asli H, Karim MR. J. Hazard. Mater. 2012, 233-234, 254.

[9] Liu ZS, Erhan SZ. J. Polym. Environ. 2010, 18, 243-249.

[10] Guo A, Javni I, Petrovic Z. J. Appl. Polym. Sci. 2015, 77, 467-473.

[11] Sahoo Sushanta K, Smita M, Nayak Sanjay K. Chin. J. Poly. Sci. 2015, 33, 137-152.

[12] Wang JC, Yang K. J. Appl. Polym. Sci. 2012, 123, 1293-1301.

[13] Gunstone FD, Padley FB. Lipid Technologies and Applications, Marcel Dekker, Inc.: New York, 1997, p. 714.

[14] Wang CH, Erhan S. J. Am. Oil Chem. Soc. 1999, 76, 1211-1216.

[15] Mert A, Brajendra KS, Neil PJP, Joseph MP, Kenneth MD. J. Am. Oil Chem. Soc. 2012, 89, 987-994.

[16] Sun LM, Feng SB. Chinese Grease 2006, 31, 58.

[17] Zhang SW. Novel Chem. Mater. 1995, 8, 25.

[18] Feng GZ, Cui YD, Lu Q. Mach. Cereals Oil Food Proc. 2005, 11, 53.

[19] Miyake Y, Yokomizo K, Matsuzaki N. J. Am. Oil Chem. Soc. 1998, 75, 1091-1094.

[20] Zhang SL. Petrochemicals 1995, 6, 71.

[21] Niu MJ. Chem. Adhes. 1997, 1, 35.

[22] Feng GZ, Li HP, Cui YD. Chem. Eng. 2007, 35, 75.

[23] Feng GZ, Qu H, Cui YD, Li HP, Lu K. J. Polym. Res. 2007, 14, $115-119$.

[24] Hwang HS, Singh M, Bakota EL, Winkler-Moser JK, Kim S, Liu SX. J. Am. Oil Chem. Soc. 2013, 90, 1705-1712.

[25] Farhoosh R, Moosavi SMR. J. Agric. Sci. Technol. 2009, 11, 173-179.

[26] Yang XH, Xia JL, Huang K. Forest Prod. Chem. Ind. 2010, 30, 31-34.

[27] Wang JC, Chen SH, Xu, ZC. Food Sci. Technol. 2012, 7, 229.

[28] Zhou B. Coat. Ind. 2007, 6, 58-60. 